\title{
Microduplication Xp11.22p11.23 syndrome
}

INSERM

\section{Source}

INSERM. (1999). Orphanet: an online rare disease and orphan drug data base.

Microduplication Xp11.22p11.23 syndrome. ORPHA:217377

Familial and de novo recurrent Xp11.22-p11.23 microduplication has been recently identified in males and females. 